\title{
Decreased production of TNF-alpha by lymph node cells indicates experimental autoimmune encephalomyelitis remission in Lewis rats
}

\author{
Juliana Seger ${ }^{1}$, Sofia Fernanda Gonçalves Zorzella-Pezavento', Ana Cláudia Pelizon'1, \\ Douglas Rodrigues Martins ${ }^{1}$, Alexandre Domingues ${ }^{2}$, Alexandrina Sartori ${ }^{1 /+}$ \\ ${ }^{1}$ Departamento de Microbiologia e Imunologia ${ }^{2}$ Departamento de Patologia, Instituto de Biociências, \\ Universidade Estadual Paulista, Botucatu, SP, Brasil
}

\begin{abstract}
Experimental autoimmune encephalomyelitis (EAE) is mediated by $C D 4^{+}$Th1 cells that mainly secrete IFN- $\gamma$ and $T N F-\alpha$, important cytokines in the pathophysiology of the disease. Spontaneous remission is, in part, attributed to the down regulation of IFN- $\gamma$ and TNF- $\alpha$ by TGF- $\beta$. In the current paper, we compared weight, histopathology and immunological parameters during the acute and recovery phases of EAE to establish the best biomarker for clinical remission. Female Lewis rats were immunised with myelin basic protein (MBP) emulsified with complete Freund's adjuvant. Animals were evaluated daily for clinical score and weight prior to euthanisation. All immunised animals developed the expected characteristics of EAE during the acute phase, including significant weight loss and high clinical scores. Disease remission was associated with a significant reduction in clinical scores, although immunised rats did not regain their initial weight values. Brain inflammatory infiltrates were higher during the acute phase. During the remission phase, anti-myelin antibody levels increased, whereas TNF- $\alpha$ and IFN- $\gamma$ production by lymph node cells cultured with MBP or concanavalin A, respectively, decreased. The most significant difference observed between the acute and recovery phases was in the induction of TNF- $\alpha$ levels in MBP-stimulated cultures. Therefore, the in vitro production of this cytokine could be used as a biomarker for EAE remission.
\end{abstract}

Key words: experimental autoimmune encephalomyelitis - tumor necrosis factor - alpha - rats inbred Lew - biomarkers

Multiple sclerosis (MS) is an inflammatory disease of the central nervous system (CNS) characterised by demyelination, $\mathrm{T}$ cell and macrophage infiltration and a decrease in neurological function (Adams et al. 1989). Experimental autoimmune encephalomyelitis (EAE) is currently considered the best available model for human MS. As such, much of our current understanding of MS originates from studies of EAE (Raine 1984, Martin \& McFarland 1995). EAE is most commonly induced by the active immunisation of animals with proteins from CNS, such as myelin proteolipid protein, myelin basic protein (MBP) or myelin oligodendrocyte glycoprotein, administered in complete Freund's adjuvant (CFA). Recent findings indicate that different cell types, including Th1, Th17, cytotoxic T cells, B cells and regulatory $\mathrm{T}$ cells are involved in the inflammatory process of both MS and EAE (Holmøy \& Hestvik 2008). Experimental evidence indicates that cytokines, such as TNF- $\alpha$, IL-6, IL-1 $\beta$ and IFN- $\gamma$, play a relevant role in the pathophysiology of both MS and EAE (Mustafa et al. 1991, Imitola et al. 2005). In the brains of MS patients and EAE rats, TNF- $\alpha$ and IFN- $\gamma$ are expressed by astrocytes, microglia and infiltrating monocytes and macrophages (Merril \& Benveniste 1996, Stanislaus et al. 1999). Moreover, antiTNF- $\alpha$ antibodies provide protection against primary

Financial support: CNPq, FAPESP

+Corresponding author: sartori@ibb.unesp.br

Received 17 November 2009

Accepted 12 March 2010 and adoptively transferred EAE (Ruddle et al. 1990, Selmaj \& Raines 1991). However, the role of IFN- $\gamma$ is more controversial. In some reports, IFN- $\gamma$ is believed to play a role in protection, whereas others suggest it promotes disease pathogenesis (Tran et al. 2000, Swanborg 2001). As a model, EAE has been induced primarily in mice, although rats are significantly more susceptible to disease development. The immunisation of Lewis rats with MBP in CFA leads to a temporary paralysis of the hind limbs that, after recovery from the clinical symptoms, results in a state refractory to active disease reinduction (Waxman et al. 1980). These pronounced characteristics between the acute and recovery phases of EAE in rats, makes this EAE rodent model more appropriate than mice to identify biomarkers that may be used to distinguish between these two disease stages. Therefore, we compared the acute and recovery phases of EAE in Lewis rats by analysing the clinical score, weight variation, histopathology, anti-myelin antibody levels and activation-induced cytokine production by spleen and lymph node cells in order to discern potential biomarkers for the recovery phase of EAE.

\section{MATERIALS AND METHODS}

Animals - Female Lewis rats (4-6 weeks old) of approximately $110-130 \mathrm{~g}$ were purchased from Multidisciplinary Center for Biological Research (UNICAMP, Campinas, SP, Brazil). The animals were given standard pellet-based food and water ad libitum. Animals were manipulated in accordance with the ethical guidelines adopted by the Brazilian College of Animal Experimentation. The experimental protocol followed was approved by the local Ethical Committee (protocol 458). 
EAE induction and evaluation - EAE was induced as previously described (Harness et al. 2003). Briefly, rats were immunised with $50 \mu \mathrm{g}$ of MBP (Sigma) emulsified with CFA containing $5 \mathrm{mg} / \mathrm{mL}$ of Mycobacterium butyricum. Animals were injected in the hind left footpad with $100 \mu \mathrm{L}$ of the emulsion and evaluated daily for weight loss and clinical score. Scoring was based on clinical manifestations according to the following parameters: 0 : no disease; 1 : loss of tonicity of the distal portion of the tail; 2: total loss of tail tonicity; 3: hind limb weakness (partial paralysis); 4: complete hind limb paralysis and urinary incontinence; 5: moribund.

Histological analysis of brain and spinal cord - The histological analysis of brain and spinal cord was performed on days 15 and 20, representing the acute and recovery phases, respectively. After euthanasia by inhalation of 5\% carbon dioxide and blood withdrawal, brain and cervical spinal cord samples were removed and fixed in a $10 \%$ solution of buffered formalin. Paraffin slides $(4-5 \mu \mathrm{m})$ were routinely stained with haematoxylin and eosin and analysed with a Leica microscope.

Quantification of perivascular inflammatory infiltrate - Quantitative evaluation of perivascular inflammatory infiltrate in the CNS was performed using a computer-assisted imaging system consisting of a Nikon Microphot-FXA optical microscope connected to a computer via a Sony Exwave HAD video camera and analysed using KS300 software (Carl-Zeiss, Germany). The total section area of each brain and spinal cord was measured to avoid any inter-animal variance. Further, perivascular mononuclear infiltrate areas of whole section were assessed by point-counting morphometry, as described elsewhere (Bock et al. 2003). The values are expressed as $\mu \mathrm{m}^{2}$ of mononuclear infiltrate per $\mathrm{mm}^{2}$ of organ section $\left(\mu \mathrm{m}^{2} / \mathrm{mm}^{2}\right)$.

Anti-myelin antibody levels - Sera were collected from euthanised rats by cardiac withdrawal at either 15 or 20 days post-EAE induction. Ninety-six well plates (Maxisorp Nunc-Immunoplates) were coated with $100 \mu \mathrm{L}$ $(5 \mu \mathrm{g} / \mathrm{mL})$ of purified MBP in coating solution $\left(\mathrm{Na}_{2} \mathrm{CO}_{3}\right.$ $17 \mathrm{mM}, \mathrm{NaHCO}_{3} 9.6 \mathrm{mM}, \mathrm{pH} 9.6$ ), incubated at $4^{\circ} \mathrm{C}$ overnight and then blocked with $200 \mu \mathrm{L}$ of phosphatebuffered saline supplemented with $0.05 \%$ Tween 20 and $10 \%$ foetal calf serum (FCS) for $1 \mathrm{~h}$ at $37^{\circ} \mathrm{C}$. Serum samples were diluted $1 / 1000$ and $1 / 5000$, added to the plates and incubated overnight at $4^{\circ} \mathrm{C}$. For the detection of specific serum IgG1 and $\operatorname{IgG} 2 \mathrm{~b}$, the plates were incubated with biotinylated mouse anti-rat antibodies (Oxford Biotechnology). After washing, plates were incubated at RT for 30 min with Streptavidin AB (Dako, Carpinteria) and then followed by chromogenic assay by adding $\mathrm{H}_{2} \mathrm{O}_{2}+$ orthophenylene-diamine (OPD - Sigma). The enzymatic reaction was stopped with $\mathrm{H}_{2} \mathrm{SO}_{4}$ and the optical density was measured at $492 \mathrm{~nm}$.

$I F N-\gamma$ and TNF- $\alpha$ production - Control and MBPimmunised rats were killed at either 15 or 20 days postimmunisation. Spleen and lymph nodes (popliteal and inguinal) were collected and the cells were adjusted to
5.0 and $2.5 \times 10^{6} / \mathrm{mL}$, respectively. Cells were cultured in complete RPMI medium (RPMI supplemented with 5\% FCS, $20 \mathrm{mM}$ glutamine and $40 \mathrm{IU} / \mathrm{mL}$ of gentamicin) in the presence of MBP $(10 \mu \mathrm{g} / \mathrm{mL})$ or concanavalin A (ConA) $(5 \mu \mathrm{g} / \mathrm{mL})$. Cytokine levels in culture supernatants were evaluated $48 \mathrm{~h}$ later by ELISA according to manufacturer's instructions (R\&D Systems, Minneapolis, MN, USA).

Statistical analysis - Data are expressed as the mean \pm standard deviation. One-way ANOVA and the Tukey test were used to compare the production of anti-myelin antibodies and cytokine levels. Weight variation and morphometric analysis of CNS were analysed by unpaired t test. Differences in which the p-value $<0.05$ were considered significant. Statistical analyses were accomplished with Minitab Software, Version 1996 (Minitab Inc, State College, PA, USA).

\section{RESULTS}

Characterisation of acute and recovery phases by clinical score - A total of eight animals, four at the acute phase and four at the recovery phase, were scored for EAE symptoms. The average body weight (Fig. 1) prior to EAE induction was $153 \mathrm{~g}$. In contrast to control animals, which gained weight over the time course measured (186 $\mathrm{g}$ at day 20), immunised animals exhibited a decrease in body weight starting at day 10 post-induction. Body weight in EAE-induced animals was significantly lower in both the acute and recovery phases compared to controls. However, no significant difference between phases was observed. Starting on day 10 or 11, immunised animals developed severe clinical manifestations, which worsened between days 13 and 15 (EAE score = 4). Similar clinical manifestations were observed in all immunised animals. Disease manifestations decreased from day 15 or 16 onward, with clinical scores at 1 or 0 by day 20 (Fig. 2).

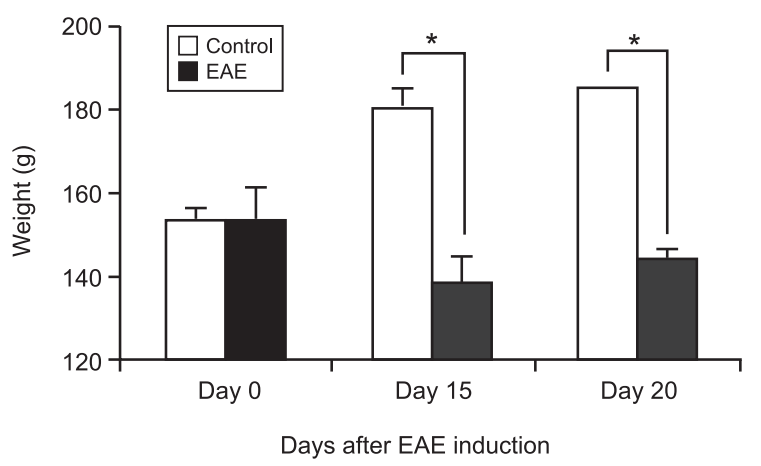

Fig. 1: weight variation in experimental autoimmune encephalomyelitis (EAE) induced in Lewis rats. The animals were immunised with myelin basic protein emulsified with complete Freund's adjuvant and weights were monitored until day 20 after disease induction. Acute (day 15) and recovery (day 20) phases were established according to the clinical score. Results are presented as mean \pm SD of four animals. Asterisk means $\mathrm{p}<0.05$. 
Histological analysis of the CNS - Typical lesions, characterised by a massive perivascular infiltration of predominantly mononuclear cells, were observed in both the brain (Fig. 3C, E) and spinal cord (Fig. 3D, F) of immunised rats. In addition, their blood vessels were congested. An initial analysis of brain (Fig. 3C, E) and cervical spinal cord sections (Fig. 3D, F) suggested that the inflammation intensity was similar between the acute (Fig. 3C, D) and recovery phases (Fig. 3E, F). However, a morphometric

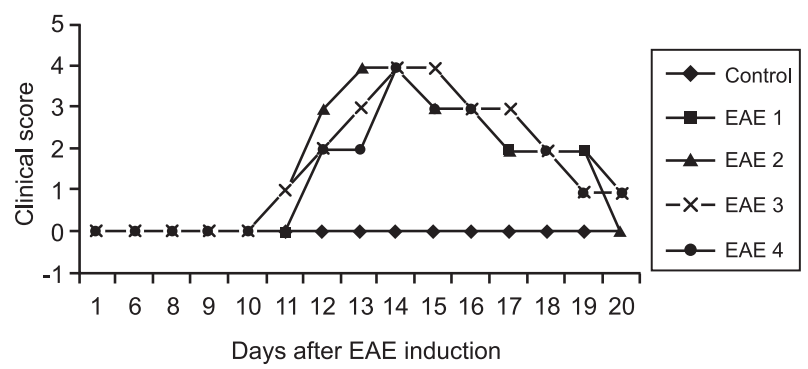

Fig. 2: clinical score variation in experimental autoimmune encephalomyelitis (EAE) induced in Lewis rats. The animals were immunised with myelin basic protein emulsified with complete Freund's adjuvant and the clinical score was daily determined until day 20 after disease induction. Signs of disease were graded as 0 : no disease; 1: loss of tonicity of the distal portion of the tail; 2: total loss of tail tonicity; 3 : hind limb weakness (partial paralysis); 4 : complete hind limb paralysis and urinary incontinence and 5: moribund. Results are presented as individual values of four animals. analysis indicated that inflammatory infiltrates were significantly higher in the brain sections of acute-phase EAE rats (Table). Spinal cord infiltrates were also more intense, although this difference was not significant (Table). No changes were observed in normal control rats, as demonstrated in Fig. 3A (brain) and Fig. 3B (spinal cord).

Specific antibody and cytokine production - The production of specific anti-myelin antibodies was significantly increased in both the acute and recovery phases of EAE-induced rats. In addition, serum IgG1 (Fig. 4A) and $\operatorname{IgG} 2 \mathrm{~b}$ (Fig. 4B) anti-myelin antibodies were significantly higher in the recovery phase.

Spleen and lymph node cells from EAE animals, restimulated in vitro with MBP, produced significantly higher IFN- $\gamma$ levels compared to control animals. How-

TABLE

Morphometric analysis of perivascular inflammatory infiltrate on central nervous system

\begin{tabular}{lcc}
\hline & $\begin{array}{c}\text { Acute phase } \\
\mathrm{n}=4\end{array}$ & $\begin{array}{c}\text { Recovery phase } \\
\mathrm{n}=4\end{array}$ \\
& $\begin{array}{c}\mu \mathrm{m}^{2} \text { of mononuclear } \\
\text { infiltrate } / \mathrm{mm}^{2} \text { of } \\
\text { organ section })\end{array}$ & $\begin{array}{c}\mu \mathrm{m}^{2} \text { of mononuclear } \\
\text { infiltrate } / \mathrm{mm}^{2} \text { of } \\
\text { organ section })\end{array}$ \\
\hline Brain & $1113.5 \pm 195.1^{a}$ & $591.1 \pm 120.8$ \\
Cervical spinal cord & $3420.4 \pm 549.6$ & $2509.1 \pm 342.9$ \\
\hline
\end{tabular}

$a: \mathrm{p}=0.017$ vs. recovery phase.
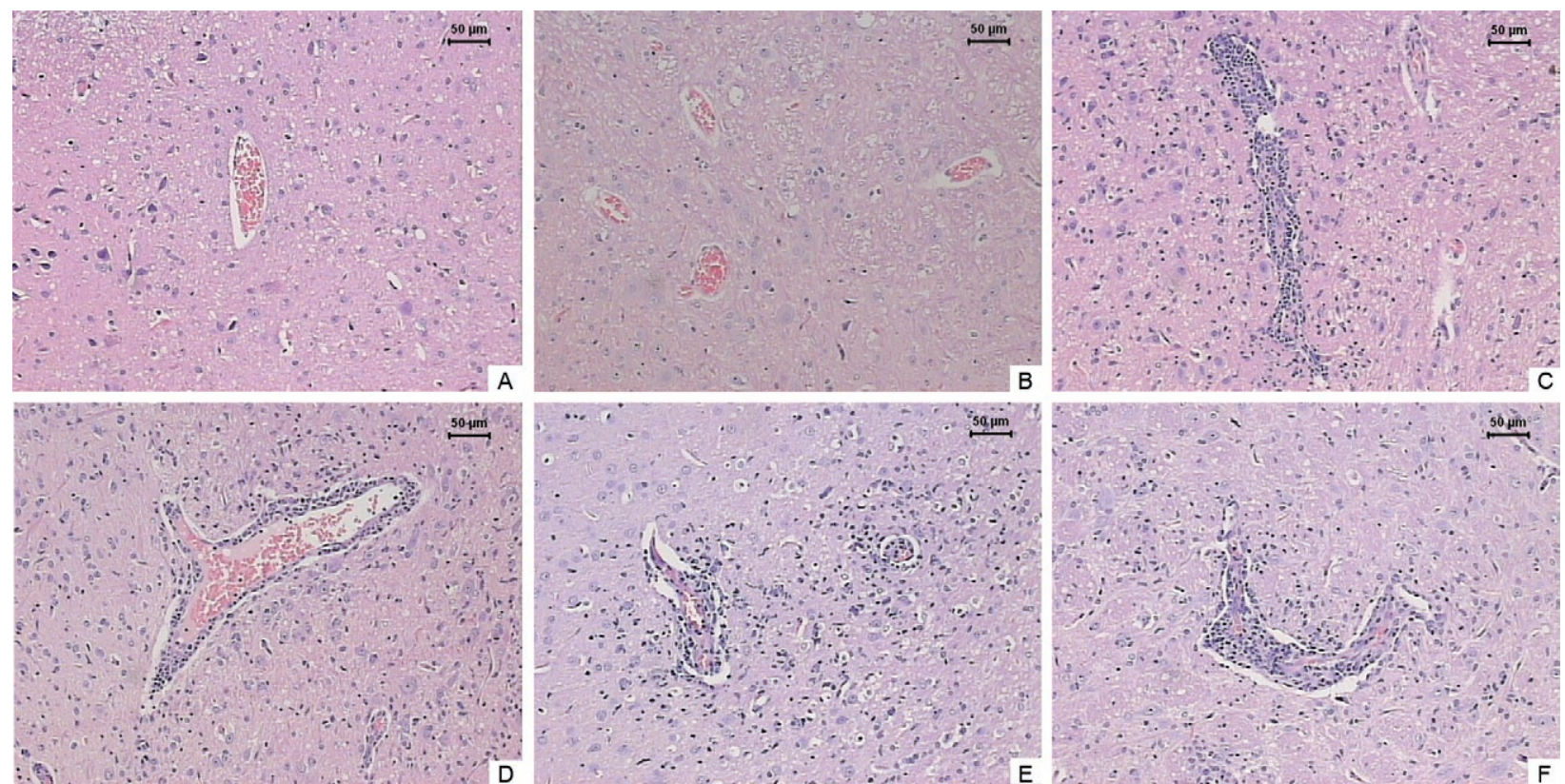

Fig. 3: histopathological analysis of central nervous system from Lewis rats with experimental autoimmune encephalomyelitis. Animals were immunised with myelin basic protein emulsified with complete Freund's adjuvant. Brain and cervical spinal cord samples were obtained during acute and recovery phases and sections were stained with haematoxylin and eosin. Samples from normal animals: A (brain) and B (spinal cord); samples from acute phase: C (brain) and D (spinal cord); samples from recovery phase: E (brain) and F (spinal cord). This analysis refers to one animal from four with very similar results. 

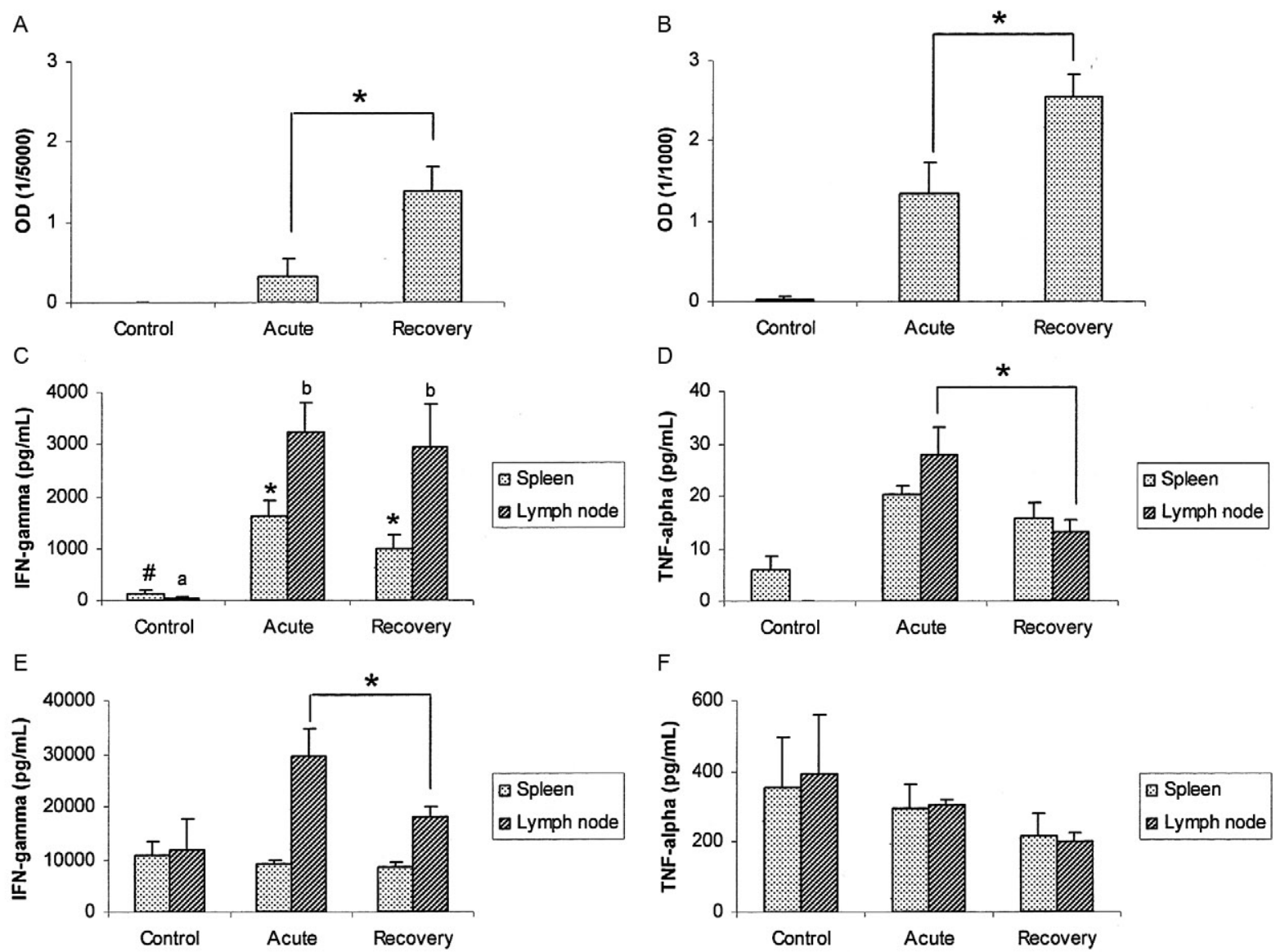

Fig. 4: seric anti-myelin antibody levels and cytokine production during acute and recovery experimental autoimmune encephalomyelitis phases. Serum samples were obtained 15 and 20 days after immunisation with myelin basic protein (MBP). The specific IgG1 (A) and IgG2b (B) levels were determined by ELISA. Spleen and lymph nodes were obtained 15 (acute phase) and 20 days (recovery phase) after immunisation with myelin, respectively. Cell cultures were stimulated with MBP (C, D) or concanavalin A (E, F), and IFN- $\gamma(\mathrm{C}, \mathrm{E})$ and TNF- $\alpha$ (D, F) were determined by ELISA. These results refer to four animals. Letters: comparison of IFN- $\gamma$ production by splenic cells among control group, acute and recovery phases. Symbols: comparison of IFN- $\gamma$ production by lymph node cells among control group, acute and recovery phases. Asterisk means $\mathrm{p}<0.05$.

ever, there were no detectable differences between the acute and remission phases in these cultures (Fig. 4C). In contrast to MBP-stimulated cultures, restimulation of lymph node cells with ConA triggered the production of significantly higher IFN- $\gamma$ levels during the acute phase, although spleen cells exhibited no difference in IFN- $\gamma$ production under these conditions (Fig. 4E). These results also differed from that of TNF- $\alpha$, where no differences between control and EAE animals or between acute and recovery phases were exhibited following ConA stimulation of either spleen or lymph node cells (Fig. 4F). However, a very clear difference was observed in the production of this cytokine by lymph node cultures stimulated with MBP. In this case, TNF- $\alpha$ levels were significantly lower during the remission phase (Fig. 4D).

\section{DISCUSSION}

All immunised rats developed severe clinical manifestations characterised by weight loss and hind limb paralysis. The acute phase of the disease peaked at day 15 and was associated with high clinical scores, represent- ing complete hind limb paralysis and the lowest weights recorded. The recovery phase occurred at day 20 , when very low clinical scores $(0$ or 1$)$ were observed and the animals began to gain weight. Previous reports in Lewis rats have described similar kinetics for the course of EAE development (Swanborg 2001, Gold et al. 2006). Histopathological analysis of brain and cervical spinal cord initially indicated similar levels of perivascular infiltrate in both the acute and recovery phases of the disease, even though decreased inflammatory infiltration during the remission phase was expected. We expected a decrease in the level of inflammatory infiltration during the remission phase because established data have shown that inflammatory cells strongly contribute to the pathology of this disease (Man et al. 2007). In addition, experimental therapeutic strategies have demonstrated a clear correlation between clinical remission and the prevention of mononuclear cell transmigration to the spinal cord (Stanislaus et al. 2001). Encephalitogenic T cells undergo apoptosis during the remission phase, which may lead to a decrease in inflammatory infiltrate with- 
in the CNS at this stage (Ishigami et al. 1998). Indeed, quantitative morphometric analysis of these infiltrates confirmed previous reports in the literature; more intense inflammation was found in brain sections from the acute phase. Nonetheless, significant inflammation was still present in the CNS during the recovery phase.

This persistence of infiltrate could, in part, be explained by the appearance of suppressor cells, which are now known as regulatory $T$ cells (Treg cells) (Welch et al. 1980). These Treg cells may be activated and gain access to the CNS where they may produce TGF- $\beta$ and/ or IL-10, thereby downregulating the production of IFN- $\gamma$ and TNF- $\alpha$.

In addition, Treg cells may prevent newly-generated encephalitogenic T cells from entering the CNS and promote autoreactive Th1 cell death by apoptosis (Karpus \& Swanborg 1991, Dore-Duffy et al. 1994, Stevens et al. 1994, Tabi et al. 1994). Recent data has demonstrated that IL-10-producing Treg cells $\left(\mathrm{CD}^{+} \mathrm{CD} 25^{+}\right)$are present in the CNS as mice enter remission (McGeachy \& Anderton 2005).

MS and EAE have traditionally been viewed as entirely $\mathrm{T}$ cell-mediated diseases, which may have delayed any investigation into the role of B cells, plasma cells and their products in the pathogenesis of MS. Regardless of the role that antibodies play in MS pathogenesis, whether the presence of serum antibodies to myelin antigens can be used as a biomarker in MS remains an important question (Ziemssen \& Ziemssen 2005). In our study, we observed a significant increase in anti-myelin antibodies of both the IgG1 and IgG2b isotypes during the remission phase of the disease. These findings suggest that augmented specific antibody levels may predict disease remission. However, this result differs from previous data that found no direct correlation between antibody titres and disease severity in EAE (Kieseier \& Hartung 2003). Recent articles show further conflicting data regarding this issue in MS patients (Cannella et al. 1998, Brundula et al. 2002, Butzkueven et al. 2002).

Many biomarkers have been suggested to help in the diagnosis, prognosis and response to therapies of MS patients. Although MS is primarily mediated by autoreactive $\mathrm{T}$ cells, the majority of biomarker candidates have resulted from studies of humoral immunity or biochemical serum parameters (Berger et al. 2003, Amorini et al. 2009). Nonetheless, a reliable indication of specific antibodies has not been shown to promote an earlier diagnosis of MS in patients (Lim et al. 2005). Cerebrospinal fluid (CSF) biomarkers also provide important and specific information because changes in the CSF composition may reflect disease mechanisms inherent to this pathology (Tumani et al. 2009). However, CSF is not easily obtained, especially in EAE models. In this context, the present results suggest that the specific induction of TNF- $\alpha$ levels from lymph node cells could be used as an immunological biomarker to characterise the recovery phase in EAE. It is tempting to hypothesise, based on the suggested role of TNF- $\alpha$ in controlling T cell inflammation in the brain, that TNF- $\alpha$-producing cells migrate from lymph nodes to the brain to contribute to autoreactive T cell apoptosis (Gold et al. 2007).
IFN- $\gamma$ production, induced by polyclonal activation by ConA, was also significantly different between the acute and remission phases of EAE. However, we believe that TNF- $\alpha$ would be a better immunological biomarker because it was specifically induced by antigen. Nonetheless, both IFN- $\gamma$ and TNF- $\alpha$ production were concomitantly reduced during the remission phase, possibly reflecting the migration of Th1 cells to the brain. This possibility is consistent with the essential role of Th1 cells in the pathogenesis of EAE through the synthesis of both IFN- $\gamma$ and TNF- $\alpha$ (McGeachy \& Anderton 2005). The possibility that non-specific T cells left the lymph nodes and accumulated in the CNS has some support in the literature; immunohistological analysis of mononuclear cell infiltration in the CNS revealed the presence of both antigen-specific and non-specific $\mathrm{CD}^{+}$ and $\mathrm{CD} 8^{+} \mathrm{T}$ cells (Hickey et al. 1983). IFN- $\gamma$ plays an important regulatory role in EAE by influencing $\mathrm{T}$ cell proliferation and directing chemokine production (Tran et al. 2000, Furlan et al. 2001). Thus, it is possible that many of these cells are not specific for myelin. This possibility is supported by the detection of a broad and non-specific regulatory effect of Treg cells in EAE (Yu et al. 2005).

Another interesting aspect was the differential production of cytokines between lymph nodes and spleen cell cultures. It was clear from the results that only cytokine production by lymph nodes differed between the two disease stages. The simplest explanation for this finding is that the predominant response occurred at the draining lymph nodes because MBP was injected subcutaneously into the footpad. It is equally possible that the specific depot effect of CFA influences this response. Recent studies have demonstrated a role for antigen persistence in the development of effector Th cells, with evidence that longterm antigen depots may contribute to localised antigenspecific T cell memory (Fazilleau et al. 2007).

Together, the present results suggest that antigeninduced TNF- $\alpha$, produced in ex vivo lymph node cell cultures, could be used as an immunological biomarker to characterise the recovery phase of EAE. Whether TNF- $\alpha$ production by peripheral blood mononuclear cells, or perhaps the TNF- $\alpha$ levels in patients' sera, exhibit a similarly predictable reduction during the remission phase of MS in patients must be thoroughly and carefully investigated.

\section{REFERENCES}

Adams CW, Poston RN, Buk, SJ 1989. Pathology, histochemistry and immunocytochemistry. J Nat Sci 92: 291-306.

Amorini AM, Petzold, A, Tavazzi B, Eikelenboom J, Keir G, Belli A, Giovannoni G, Di Pietro V, Polman C, D’Urso S, Vagnozzi R, Uitdehaag B, Lazzarino G 2009. Increase of uric acid and purine compounds in biological fluids of multiple sclerosis patients. Clin Biochem 42: 1001-1006.

Berger T, Rubner P, Schautzer F, Egg R, Ulmer H, Mayringer I, Dilitz E, Deisenhammer F, Reindl M 2003. Antimyelin antibodies as a predictor of clinically definite multiple sclerosis after a first demyelinating event. $N$ Eng J Med 349: 139-145.

Bock T, Pakkenberg B, Buschard K 2003. Increased islet volume but unchanged islet number in ob/ob mice. Diabetes 52: 1716-1722.

Brundula V, Rewcastle NB, Metz LM, Bernard CC, Young VW 2002. 
Targeting leukocyte MMPs and transmigration: minocycline as a potential therapy for multiple sclerosis. Brain 125: 1297-1308.

Butzkueven H, Zhang JG, Soilu-Hanninen M, Hochrein H, Chionh F, Shipham K.A 2002. LIF receptor signaling limits immunemediated demyelination by enhancing oligodendrocyte survival. Nat Med 8: 613-619.

Cannella B, Hoban CJ, Gao YL, Garcia-Arenas R, Lawson D, Marchionni M 1998. The neuregulin, glial growth factor 2, diminishes autoimmune demyelination and enhances remyelination in a chronic relapsing model for multiple sclerosis. Proc Nat Acad Sci USA 95: 10100-10105.

Dore-Duffy P, Balabanov R, Washington R, Swanborg RH 1994. Transforming growth factor $\beta 1$ inhibits cytokine-induced CNS endothelial cell activation. Molec Chem Neuropathol 22: 161-175.

Fazilleau N, McHeyzer-Williams LJ, McHeyzer-Williams MG 2007. Local development of effector and memory T helper cells. Curr Opin Immunol 19: 259-267.

Furlan R, Brambilla E, Ruffini F, Poliani PL, Bergami A, Marconi PC, Franciotta DM, Penna G, Comi G, Adorini L, Martino G 2001. Intrathecal delivery of IFN-gamma protects C57BL/6 mice from chronic-progressive experimental autoimmune encephalomyelitis by increasing apoptosis of central nervous system-infiltrating lymphocytes. J Immunol 67: 1821-1829.

Gold R, Linington C, Lassmann H 2006. Understanding pathogenesis and therapy of multiple sclerosis via animal models: 70 years of merits and culprits in experimental encephalomyelitis research. Brain 129: 1953-1971.

Gold R, Linker RA, Chan A 2007. Termination of inflammation in the nervous system. Rev Neurol 163: 672-676.

Harness J, Cavanagh A, Morton H, McCombe P 2003. A protective effect of early pregnancy factor on experimental autoimmune encephalomyelitis induced in Lewis rats by inoculation with myelin basic protein. J Neurol Sci 216: 33-41.

Hickey WF, Gonatas NK, Kimura H, Wilson DB 1983. Identification and quantitation of T lymphocyte subsets found in the spinal cord of the Lewis rat during acute experimental allergic encephalomyelitis. J Immunol 131: 2805-2809.

Holmøy T, Hestvik AL 2008. Multiple sclerosis: immunopathogenesis and controversies in defining the cause. Curr Opin Infect Dis 21: $271-278$.

Imitola J, Chitnis T, Khoury SJ 2005. Cytokines in multiple sclerosis: from bench to bedside. Pharmacol Ther 106: 163-177.

Ishigami T, White CA, Pender MP 1998. Soluble antigen therapy induces apoptosis of autoreactive T cells preferentially in the target organ rather than in the peripheral lymphoid organs. Eur J Immunol 28: 1626-1635.

Karpus WJ, Swanborg RH 1991. CD4 $4^{+}$suppressor cells inhibit the function of effector cells of experimental autoimmune encephalomyelitis through a mechanism involving transforming growth factor-beta. J Immunol 146: 1163-1168.

Kieseier BC, Hartung HP 2003. Multipleparadigm shifts in multiple sclerosis. Curr Opin Neurol 16: 247-252.

Lim ET, Berger T, Reindl M, Dalton CM, Fernando K, Keir G, Thompson EJ, Giovannoni G 2005. Anti-myelin antibodies do not allow earlier diagnosis of multiple sclerosis. Mult Scler 11: 492-494.

Man S, Ubogu EE, Ransohoff RM 2007. Inflammatory cell migration into the central nervous system: a few new twists on an old tale. Brain Pathol 17: 243-250.
Martin R, McFarland HF 1995. Immunological aspects of experimental allergic encephalomyelitis and multiple sclerosis. Crit Rev Clin Lab Sci 32: 121-182.

McGeachy MJ, Anderton SM 2005. Cytokines in the induction and resolution of experimental autoimmune encephalomyelitis. $C y$ tokine 32: 81-84.

Merril JE, Benveniste EM 1996. Cytokines in inflammatory brain lesions: helpful and harmful. Trends Neurosci 19: 331-338

Mustafa MI, Diener P, Höjeberg B, Van der Meide P, Olsson T 1991. $\mathrm{T}$ cell immunity and interferon- $\gamma$ secretion during experimental allergic encephalomyelitis in Lewis rats. J Neuroimmunol 31: 165-177.

Raine CS 1984. Biology of disease. Analysis of autoimmune demyelination: its impact upon multiple sclerosis. Lab Invest 50: 608-635.

Ruddle NH, Bergman CM, McGrath ML, Lingenheld EG, Grunnet ML, Padula SJ, Clark RB 1990. An antibody to lymphotoxin and tumor necrosis factor prevents transfer of experimental allergic encephalomyelitis. J Exp Med 172: 1193-1200.

Selmaj K, Raines CS, Cross AH 1991. Anti-tumor necrosis factor therapy abrogates autoimmune demyelination. Ann Neurol 30: 694-700.

Stanislaus R, Pahan K, Singh AK, Singh I 1999. Amelioration of experimental allergic encephalomyelitis in Lewis rats by Lovastatin. Neurosci Lett 269: 71-74.

Stanislaus R, Singh AK, Singh I 2001. Lovastatin treatment decreases mononuclear cell infiltration into the CNS of Lewis rats with experimental allergic encephalomyelitis. $J$ Neurosci Res 66: 155-162.

Stevens DB, Gould KE, Swanborg RH 1994. Transforming growth factor- $\beta 1$ inhibits tumor necrosis factor-TNF- $\alpha /$ lymphotoxin production and adoptive transfer of disease by effector cells of autoimmune encephalomyelitis. J Neuroimmunol 51: 77-83.

Swanborg RH 2001. Experimental autoimmune encephalomyelitis in the rat: lessons in T-cell immunology and autoreactive. Immunol Rev 184: 129-135.

Tabi Z, McCombe PA, Pender MP 1994. Apoptotic elimination of $\mathrm{V} \beta 8.2^{+}$cells from the central nervous system during recovery from experimental autoimmune encephalomyelitis induced by passive transfer of V $\beta 8.2^{+}$encephalitogenic T cells. Eur J Immunol 24: 2609-2617.

Tran EH, Prince EN, Owens T 2000. IFN-gamma shapes immune invasion of the central nervous system via regulation of chemokines. J Immunol 164: 2759-2768.

Tumani H, Hartung HP, Hemmer B, Teunissen C, Deisenhammer F, Giovannoni G, Zettl UK, BioMS Study Group 2009. Cerebrospinal fluid biomarkers in multiple sclerosis. Neurobiol Dis 35: 117-127.

Waxman FJ, Fritz RB, Hinrichs DJ 1980. The presence of specific antigen-reactive cells during the induction, recovery and resistance phases of experimental allergic encephalomyelitis. Cell Immunol 49: 34-42.

Welch AM, Holda JH, Swanborg RH 1980. Regulation of experimental allergic encephalomyelitis. II. Appearance of suppressor cells during the remission phase of the disease. J Immunol 125: 186-189.

Yu P, Gregg RK, Bell JJ, Ellis JS, Divekar R, Lee HH, Jain R, Waldner H, Hardaway JC, Collins M, Kuchroo VK, Zaghouani H 2005. Specific $\mathrm{T}$ regulatory cells display broad suppressive functions against experimental allergic encephalomyelitis upon activation with cognate antigen. J Immunol 174: 6772-6780.

Ziemssen T, Ziemssen F 2005. The role of the humoral immune system in multiple sclerosis (MS) and its animal model experimental autoimmune encephalomyelitis (EAE). Autoimmun Rev 4: 460-467. 